\title{
Hedging Foreign Exchange Risk Exposure by Importer Companies
}

\author{
Kazi Rashedul Hasan \\ Department of Finance, American International University-Bangladesh, Dhaka, Bangladesh \\ Email address: \\ kazihasan@aiub.edu \\ To cite this article: \\ Kazi Rashedul Hasan. Hedging Foreign Exchange Risk Exposure by Importer Companies. International Journal of Economics, Finance and \\ Management Sciences. Vol. 3, No. 5, 2015, pp. 435-440.doi: 10.11648/j.ijefm.20150305.14
}

\begin{abstract}
The study was conducted in order to disclose the Foreign Exchange (FX) rate risk faced by every importer company. The paper investigates FX risk hedging strategy using forwards versus floating strategy in terms of minimizing total importing costs. The study exposes real-life costs of hedging strategies using forwards comprising theoretical foundations as well as practical implementation example based on real company data. The main question to be answered in the paper is whether it is beneficial to hedge with FX forwards or it is better to float FX exposure.
\end{abstract}

Keywords: Probability Distribution, Pearson's Chi-squared Test, Monte Carlo Simulation, Forward Contracts, Foreign Exchange

\section{Introduction}

Instability of foreign currency exchange rates is one of the most challenging and concerning topics in economies of many countries. Some companies and even individuals have loans to be paid in foreign currency while earning revenues in domestic currency. Situation might be worse for the companies or individuals that have external trades exporters and importers. Exporter companies have a risk to lose part of their profit if domestic currency appreciates and vice versa is true for importer companies, they would lose if domestic currency depreciates.

Everyday purchase decisions for importing goods bear a foreign exchange rate risk due to possible high fluctuations on foreign exchange (ForEx, FX) market.

Exchange rate risk makes the economic planning process for businesses more difficult and financial outcomes uncertain. Companies facing exchange rate risk exposure have to reduce or eliminate foreign exchange risks in order to ensure profitability.

Main goal of the paper is to illustrate hedging strategy using FX forwards against the product costs in foreign currency incurred by importer companies.

Developed analysis and methods are illustrated on the example of international online retail store that sells products in USD but acquires products from all over the world, thus bearing FX risk exposure. As an illustrative example, this paper focuses on company's products acquired in European countries. Therefore, the paper presents a problem of hedging USD/EUR exchange rate risk for the company who buys in EUR currency and sells in USD. In other words, company receives revenues in one currency, while committing its liabilities in different currency. So, buying in one currency and selling in another exposes a foreign exchange rate risk.

Any importer of the foreign goods is actively involved in foreign exchange market, which in turn exposes the company to foreign exchange rate risk. As a result, findings of the paper can be valuable for every importer company in the world and any company that is exposed to FX risk.

Even though, a methodology used in this paper is illustrated on the example of hedging USD/EUR exchange rate risk, the methods and applications developed herein can easily be replicated for any FX rate couples.

Next section provides a literature review of the material that is relevant to the methods applied in the paper. The literature reviews aims to narrow the scope of what can be read for comprehensive understanding of the theories and applications used in this paper.

Further, the paper considers historical costs data using descriptive statistics like diagrams and histograms. At the same time, distribution fitting technique, named Pearson's Chi-squared $\left(\chi^{2}\right)$ Test is used to make inferences about the probability distribution of historical data. This sort of statistical analysis is important for generating possible future costs of a particular company. 
In the section, named "Foreign Exchange Risk Hedging Strategy", the paper introduces theoretical foundations of hedging strategies for minimizing FX risk exposure. It briefly explains three main ways of dealing with FX risk exposure. Those are: keeping constant profit margins strategy, natural hedge, and hedging using forward contracts. The latter one uses derivative instrument, called forward contract. Essentially, forwards contracts are financial instruments that allow companies and investors to set today the terms of future transactions. This way, using FX forward contracts companies and individuals can guarantee predetermined exchange rate for the transactions that will occur in a future.

Final section addresses the main question of the research paper - whether it is beneficial to hedge with FX forwards or it is better to float FX exposure - by calculating average daily costs with hedging FX risk exposure and without hedging.

In conclusion, main results are emphasized once more. Given example favored floating exposure strategy with expected reduction in daily costs of 67 US dollars.

\section{Literature Review}

Research paper examines hedging strategies using forward contracts for managing FX risk exposure while describing detailed statistical methods and implementation tools for practical application of FX risk hedging process.

Some statistical references are given for probability theory and distributions. Distribution fitting techniques used in this article are discussed by Bagdonavicius (2011) and Moschopouolos (1985). Some descriptive statistical methods used in the paper are discussed by Hogg and Craig (1995), Carlson and Thorne (1997) and even more comprehensive applications of statistics for business and economics is discussed by Newbold, Carlson, Thorne (2007). Besides distribution fitting techniques, Hanke and Reitsch (1995) discuss other business forecasting methods for generating future possible outcomes.

Further studies reviewed for this paper discuss derivatives markets and hedging strategies using forwards and futures contracts. Papers that examined futures pricing include Modest and Sundaresan (1983), Cornell and French (1983), which emphasizes tax effects in futures pricing, and French (1983), which compares forwards and futures when both exist on the same underlying asset. Brennan and Schwartz (1990) explore optimal arbitrage when there are transaction costs, and Reinganum (1986) explores the arbitrage possibilities inherent in time travel. There is a more technical academic literature focusing on the difference between forward and futures contracts, including Black (1976a), Cox et al. (1981), Richard and Sundaresan (1981), and Jarrow and Oldfield (1981).

Derivatives markets and derivative instruments are broadly discussed by Hull (2012) and by McDonald (2012). FX risk management is discussed as a part of financial institutions risk management by Sounders and Cornett (2008), and by Hull (2010). Risk management tools using derivatives securities are further discussed by Gastineau, Smith, Todd (2001), and by Petersen and Thiagarajan (2000).

Finally, this paper includes literature from specific discussions of foreign currency derivatives, valuation and hedging with and without derivatives referring to Allayannis and Weston (2001) about the use of foreign currency derivatives, Brown (2001) about managing FX risk with derivatives, and Campbell, Medeiros and Viceira (2010) about global currency hedging.

References given above outline all major trends in the research of FX risk exposure problems, its hedging and statistical background necessary to implement hedging strategies based on real-life business cases. Further studies should be focusing more on combination of theoretical backgrounds and mathematical models for clearer view of the use of hedging strategies in practice. Next sections of the paper give one example of such practical implementation.

\section{Cost Data Statistical Analysis}

This part of the paper is devoted to statistical analysis of the costs faced by importer companies. Statistical analysis is crucial for understanding the cost structure of the company and making accurate predictions about the expected costs in the future. To illustrate the methodology for analyzing statistical data and making future projections, past data of the costs of international online retail store 1 is used. The store represents an importer company that sells products in USD but acquires products from all over the world. As an illustrative example, this paper focuses on company's products acquired in European countries. As can be seen on Fig. 1, daily costs data is denominated in EUR currency and has considerably high volatility during the given period from Aug-2014 till Aug-2015.

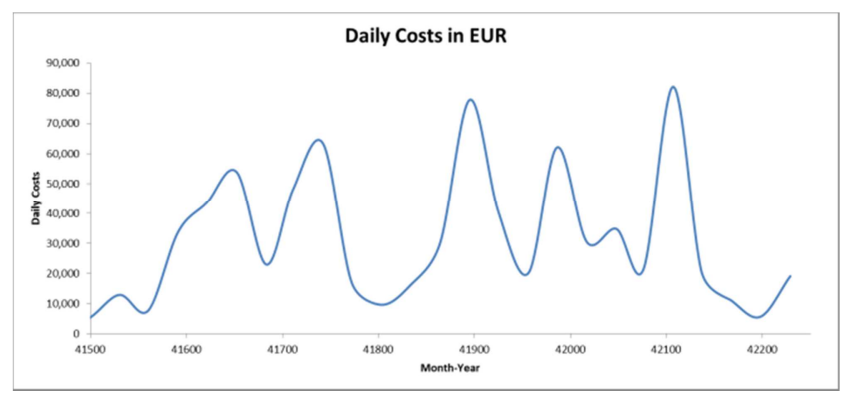

Figure 1. Daily Costs in EUR.

Highly volatile cost structure is associated with higher uncertainty about the amount of foreign currency needed at a particular point in time. Natural way for predicting future outflows is to simulate random variables using the statistical distribution of historical data. This section presents distribution fitting techniques, namely Pearson Chi-squared Test $\left(\chi^{2}\right)$ method for making inferences about the distribution of historical data. The easiest way for looking at the nature of

1 Per request of the management, exact name of the store has not been mentioned due to confidentiality issues and sensitive nature of the data. 
historical data is to construct a histogram, a graphical representation of past distribution (see Fig. 2).

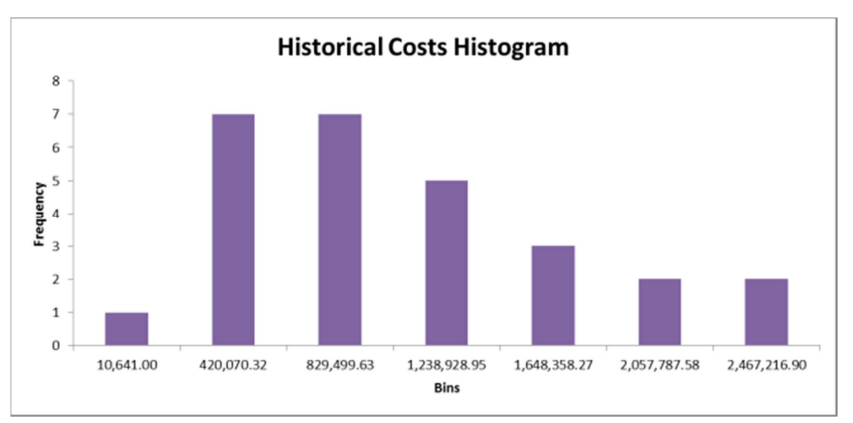

Figure 2. Historical Costs Histogram.

Most common distributions applied for fitting purposes are: Normal Distribution, Gamma Distribution and Lognormal distribution. Normal Distribution is not considered because it takes negative values and the cost figures cannot be negative. On the other hand, looking at Fig. 2 it can easily be seen that histogram resembles Gamma or Lognormal distribution. Using Pearson's Chi-squared Test procedure, it is checked whether historical data follows Gamma or Lognormal distribution.

The procedure of the test includes the following steps:

1. Calculate the chi-squared test statistic, $\chi 2$;

2. Determine the degrees of freedom;

3. Compare $\chi^{2}$ to the critical value, $\mathrm{p}$ of chi-squared distribution.

The value of test statistic is:

$$
\chi^{2}=\sum_{i=1}^{N} \frac{\left(O_{i}-E_{i}\right)^{2}}{E_{i}}
$$

Where

$O_{i}$ - an observed (historical) frequency,

$E_{i}$ - an expected (theoretical) frequency,

$N$ - number of frequency intervals.

According to the above, following is calculated from historical data:

Table 1. Cost Data Parameters.

\begin{tabular}{ll}
\hline$\mu$ & $29,343.81$ \\
$\sigma$ & $22,926.49$ \\
$\min$ & 355 \\
$\max$ & 82,241 \\
skew & 0.87744179 \\
kurt & -0.032596395 \\
count & 27 \\
\hline
\end{tabular}

Where

$\mu-$ is average daily cost,

$\sigma-$ is standard deviation,

min - lowest cost value,

max - highest cost value,

skew - skewness,

kurt-kurtosis,

count-number of observations.

Further, the number of bins or frequency intervals, $k$ and the length of the interval, $l$ can be calculated as:

$$
\begin{gathered}
k=1+\log _{2}(\text { count })+\log _{2}\left(1+\frac{\text { skew }}{\sigma_{\text {skew }}}\right) \\
l=\frac{\max -\min }{k}
\end{gathered}
$$

Now, checking for Gamma Distribution with alpha, $\alpha$ and beta, $\beta$ parameters:

$$
\alpha=\frac{\mu^{2}}{\sigma^{2}} \quad \text { and } \beta=\frac{\sigma^{2}}{\mu}
$$

According to calculations resulted in $p$-value of $63.93 \%$, it is finally concluded that histogram of historical costs follows Gamma Distribution with the following alpha and beta parameters:

Table 2. Alpha and Beta coefficients of Gamma Dist.

\begin{tabular}{ll}
\hline$\alpha$ & 1.64 \\
$\beta$ & $17,912.60$ \\
\hline
\end{tabular}

Moreover, observed historical and expected distributions for the past costs data are plotted on Fig. 3, where it is graphically illustrated that cost distribution obviously resembles Gamma distribution.

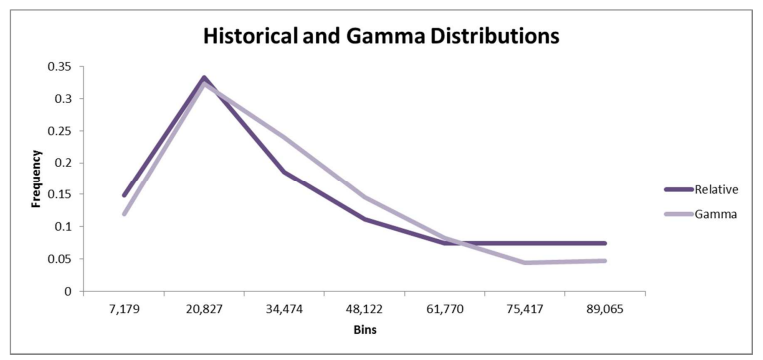

Figure 3. Graphical representation of Historical and Gamma Distributions.

Using distribution fitting techniques like Pearson's Chisquared $\left(\chi^{2}\right)$ Test companies can accurately model expected values of their sales, costs, production or any other relevant figures.

\section{Foreign Exchange Risk Hedging Strategy}

One way to avoid market fluctuations is to use a hedging strategy. A hedging strategy designed to lock in costs or prices can protect Importer Company from high volatilities on FX markets. This section further focuses on FX risk exposure faced by importer companies and introduces several ways that might be used for minimizing FX risk. Three main ways of dealing with FX risk exposure are discussed below:

- Constant Profit Margins;

- Natural Hedge;

- Forward Contracts.

\subsection{Constant Profit Margins}

Depending on the industry and particular company's market share, FX rate fluctuations can be reduced by freezing profit margins. In essence, this implies that company adopts a 
constant profit margins strategy, which in turn means that change in the acquisition cost of products will be reflected in their selling price as well.

So, if FX rate of the cost currency will increase, Importer Company will increase the selling price of the products acquired in that currency accordingly, thus maintaining constant profit margin.

Of course, some companies might not decrease the selling price with the decrease in FX rate, though it will be hard to explain to their loyal customers. Another complication with this strategy is that some companies might not be in the position of increasing selling price due to facing tough competition from rival companies.

\subsection{Natural Hedge}

The optimal way of hedging is natural hedging - where the adverse impact of FX rate variations on cash inflows are offset by the effect on cash outflows, or vice versa.

A natural hedge is the reduction in risk that can arise from an institution's normal operating procedures. A company with significant sales in one country holds a natural hedge on its currency risk if it also generates expenses in that currency. For example, an oil producer with refining operations in the US is (partially) naturally hedged against the cost of dollardenominated crude oil.

Natural hedging implies conducting business processes in a way that the currencies of cash inflows and outflows (revenues and expenses) are matched. This enables the FX risk to be minimized. More generally, exchange rate exposure can be reduced by matching foreigncurrency revenues with expenses in foreigncurrency.However, while a company can alter its operational behavior to take advantage of a natural hedge, such hedges might not very flexible for many companies.

\subsection{Forward Contracts}

Forward contracts - which permit firms and investors to guarantee a price for a future purchase or sale - area basic financial risk management tool.

By definition, a forward contract is a binding agreement (obligation) to buy/sell an underlying asset in the future, at a price set today. So, namely, currency forwards are agreements when one party buys a certain currency from another party on a future date with a predetermined exchange rate set today. By fixing an exchange rate for a future period the volatility of exchange rate movement is covered (within the contract period). If one expects to receive or pay foreign currency at a future date, a foreign currency forward contract can be used to lock in the exchange rate.

Currency futures and forwards are widely used to hedge against changes in exchange rates. Futures contracts are the same as forwards in principle except for some institutional and pricing differences.

Many corporations use currency futures and forwards for short-term hedging. An importer of consumer electronics, for example, may have an obligation to pay the manufacturer 15 million Euros 90 days in the future. The dollar revenues from selling these products are likely known in the short run, so the importer bears pure exchange risk due to the payable being fixed in Euros. By buying EUR 15 million 90 days forward, the importer locks in a dollar price to pay for the EUR, which will then be delivered to the manufacturer.

Price of the currency forward, or future exchange rate set in FX forward is calculated by:

$$
f_{0, t}=x_{0} e^{\left(r_{d}-r_{f}\right) t}
$$

Where,

$f_{0, t}-$ Future exchange rate at time, $t$;

$x_{0}$ - Current exchange rate for $\mathrm{d} / \mathrm{f}$ couple;

$r_{d}$ - Domestic risk-free interest rate;

$r_{f}$ - Foreign risk-free interest rate;

$t$-Settlement date of the forward contract.

Future exchange rate is locked in forward or futures contract and is guaranteed effective rate for future transaction. So, with FX forward or futures contracts fluctuations on FX market no longer affect the acquisition cost of products in foreign currency, it is fixed in advance as future exchange rate defined in forward or futures contract.

\section{Hedged and Not Hedged Cost Valuation}

This part of the paper comprises results and theoretical foundation derived in parts 3 and 4, respectively. Namely, this sections presents costs valuation for international online store with using forwards for FX risk hedging and without it. So, the comparison of FX risk hedging strategy using forwards and FX risk floating strategy is given below.

In part 3, main results summarized that historical daily costs of production in EUR currency follow Gamma distribution with alpha, $\alpha=1.64$ and beta, $\beta=17,912.60$. This information is enough to run forecasts of future expected costs using Monte Carlo Simulation technique.

Generally, it is defined as a computerized mathematical technique that allows people to account for risk in quantitative analysis and decision making. We can narrow the definition of Monte Carlo Simulation to a problem solving technique used to approximate the probability of certain outcomes by running multiple trial runs, called simulations, using random variables.

To apply this technique for generating future expected daily costs of production in EUR currency, following Excel formula is used:

$$
\text { GAMMAINV(RAND(), alpha, beta) }
$$

Where

GAMMAINV - the inverse of the gamma cumulative distribution;

$R A N D$ () - Returns an evenly distributed random real number greater than or equal to 0 and less than 1 .

Substituting alpha and beta parameter values derived 
above, expected daily costs for the period between Aug-2014 and Aug-2015 is simulated.

Further, expected daily cost of floating strategy and hedging using forwards strategy must be calculated. For this purpose, spot and one-month forward USD/EUR exchange rates for the same period were extracted from Bloomberg:

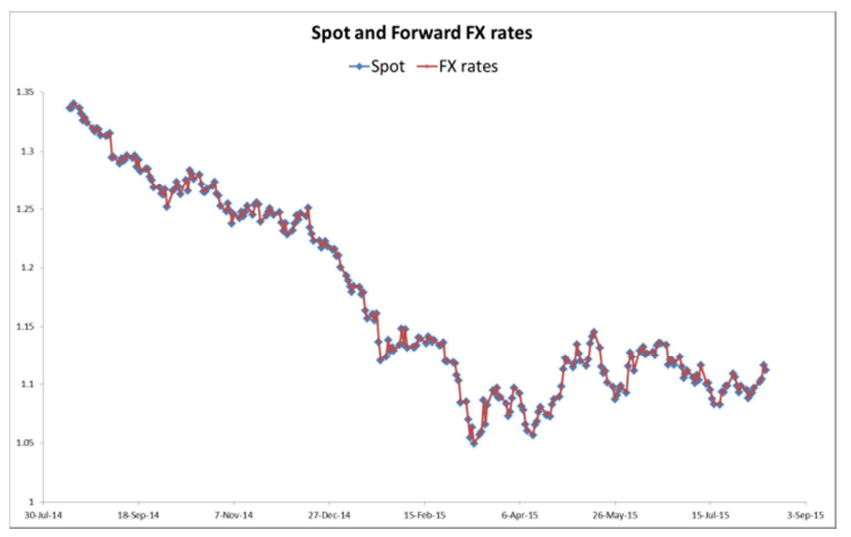

Figure 4. Spot and one-month forward FX rates.

Fig. 4 illustrates how closely spot (current) and one-month forward exchange rates move. Spot FX rates are in blue color that is seen behind one-month forward FX rates in red color.

To be complete, spot FX rate is foreign exchange rate effective immediately, and one-month forward FX rate is future exchange rate guaranteed by the forward contract for the transaction in one month. By entering into forward contracts, the online store or any other importer company can guarantee following FX rates for monthly transactions:

Table 3. One-month forward rates.

\begin{tabular}{llll}
\hline Month & Frate & Month & Frate \\
\hline Aug-14 & 1.3366 & Mar-15 & 1.0500 \\
Sep-14 & 1.2966 & Apr-15 & 1.0571 \\
Oct-14 & 1.2755 & May-15 & 1.1358 \\
Nov-14 & 1.2480 & Jun-15 & 1.1271 \\
Dec-14 & 1.2465 & Jul-15 & 1.1007 \\
Jan-15 & 1.1777 & Aug-15 & 1.1124 \\
Feb-15 & 1.1397 & & \\
\hline
\end{tabular}

Source: Bloomberg.

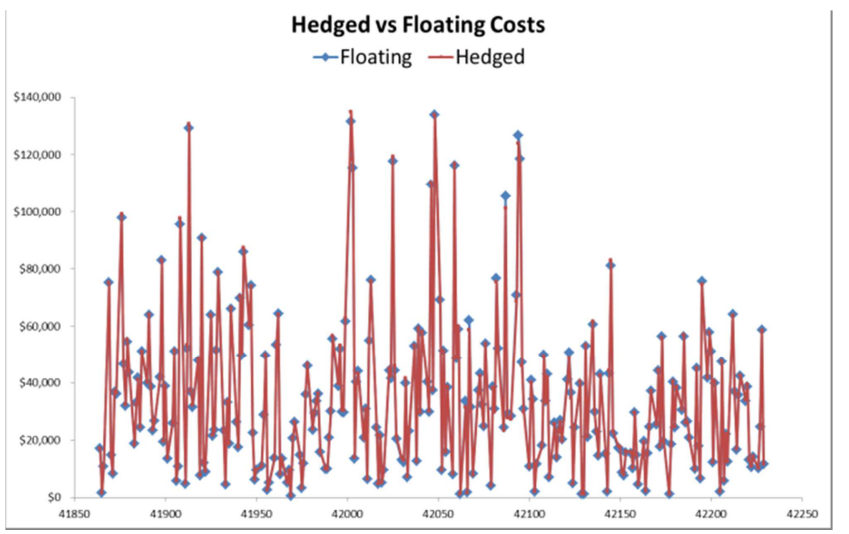

Figure 5. Hedged and Not Hedged acquisition costs.

Now, using spot and forward FX rates data, floating FX exposure and hedging FX risk strategies can be valued. Floating FX exposure strategy is valued by calculating acquisition costs in US dollars using everyday spot USD/EUR rates. While hedging with forwards strategy is valued by calculating acquisition costs with fixed forward FX rates per month according to table (3). Fig. 5 graphs simulated costs from both strategies (floating strategy in blue, and hedging - in red). It is easily seen that there is no big differences between the costs of both strategies.

Average daily cost within the period of one year using floating strategy resulted into $\$ 34,191$ and using hedging strategy average daily cost was $\$ 34,231$.

Table 4. Average daily costs under both strategies.

\begin{tabular}{lll}
\hline & Daily & Monthly \\
\hline E [C] w/o hedge & $\$ 34,191$ & $\$ 1,025,726$ \\
E [C] with hedge & $\$ 34,231$ & $\$ 1,026,941$ \\
\hline
\end{tabular}

Where

$\mathrm{E}[\mathrm{C}]$ w/o hedge - average daily cost of floating strategy;

E [C] with hedge- average daily cost of hedging strategy.

This gives $\$ 41$ difference between two strategies in favor of floating. To cover all possible outcomes, the cost difference has been simulated 500 times using Monte Carlo Simulation. Average difference of 500 simulations resulted into \$67. Other figures are summarized below:

Table 5. Summary of 500 cost difference simulations.

\begin{tabular}{ll}
\hline $\mathrm{E}[\mathrm{H}-\mathrm{NH}]$ & $\$ 67$ \\
$\sigma$ & $\$ 29$ \\
upper $(95 \%)$ & $\$ 70$ \\
lower $(95 \%)$ & $\$ 65$ \\
\hline
\end{tabular}

Where

$E[H-N H]$ - average cost difference;

$\sigma$ - standard deviation of differences;

upper - maximum value with $95 \%$ confidence;

lower - minimum value with $95 \%$ confidence.

Above summary outlines exact cost value difference between floating and hedging strategy given FX market spot and one-month forward rates during the period of one year, (Aug-2014 - Aug-2015). Even though, this example favors floating strategy, this is not necessarily always true. Data used in example included only one particular year's spot and forward rates, while different years will yield different rates and could yield to different conclusions about the strategy.

Example in this paper favored floating FX exposure strategy, but the same analysis methodology could be used with any other cost structure or FX rates pair.

\section{Conclusions}

Study illustrated distribution fitting and FX risk exposure hedging methods on the example of an Importer Company, international online retail store. However, methods and applications developed are useful for every company facing FX risk exposure.

In comparison of hedging FX risk using forward contracts and floating FX risk exposure, given example favored 
floating exposure strategy with expected reduction in daily costs of 67 US dollars.

It is important to emphasize that result for different companies and FX currency pairs will differ in favor of either hedging or floating strategy. A particular example in the paper was presented for illustration purposes only. The scope of the research paper aimed to fully present and illustrate a specific methodology for managing FX risk exposure that can be used for any FX pair and by any company or individual.

\section{References}

[1] V. N. Bagdonavicius," Chi-squared goodness-of-fit test for right censored data", The International Journal of Applied Mathematics and Statistics, p. 30-50, 2011.

[2] P. G. Moschopoulos, "The distribution of the sum of independent gamma random variables", Annals of the Institute of Statistical Mathematics, 1985.

[3] R. Hogg, and A. Craig, "Mathematical Statistics", 5th ed. Englewood Cliffs, NJ: Prentice Hall, 1995.

[4] W. L. Carlson, and B. Thorne, "Applied Statistical Methods for Business and Economics”, NJ: Prentice Hall, 1997

[5] P. Newbold, W. L. Carlson, B. Thorne, "Statistics for Business and Economics", $6^{\text {th }}$ ed., Pearson Education, 2007.

[6] J. E. Hanke, A. G. Reitsch, "Business Forecasting", $5^{\text {th }}$ ed., Prentice Hall, Englewood Cliffs, 1995.

[7] J. C. Hull, "Options, futures, and other derivatives", Prentice Hall, 2012.

[8] R. L. McDonald, "Derivatives Markets", New York: Addision Wesley, 2012.
[9] A. Sounders, M. M. Cornett, "Financial Institutions Management", $6^{\text {th }}$ international ed., McGraw-Hill, 2008.

[10] J. C. Hull, "Risk Management and Financial Institutions", $2^{\text {nd }}$ ed., Pearson, 2010

[11] G. L. Gastineau, D. J. Smith, and R. Todd, "Risk Management, Derivatives, and Financial Analysis under SFAS No. 133", The Research Foundation of AIMR and Blackwell Series in Finance, 2001.

[12] M. A. Petersen, and S. R. Thiagarajan, "Risk Management and Hedging: With and Without Derivatives", Financial Management, 29, 4 (Winter 2000): 5-30.

[13] G. Allayannis, and J. Weston, "The Use of Foreign Currency Derivatives and Firm Market Value", Review of Financial Studies, 14, 1 (Spring 2001): 243 - 76.

[14] G. W. Brown, "Managing Foreign Exchange Risk with Derivatives", Journal of Financial Economics, 60 (2001): 40148.

[15] J. Y. Campbell, K. S. Medeiros, and L. M. Viceira, "Global Currency Hedging", Journal of Finance, 62, 1 (February 2010): 87-121.

[16] C. Geczy, B. A. Minton, and C. Schrand, "Why Firms Use Currency Derivatives", Journal of Finance, 52, 4 (1997): 1323-54.

[17] Griffin, "HRM - Human Resource Management", New York, Pearson, 2009.

[18] C. Julmi, "Introduction to Game Theory", Copenhagen: Book Boo N, 2012.

[19] Mankiw, "Principles of Economics", $5^{\text {th }}$ ed., South-western Cengage Learning, 2011.

[20] F. J. Jones, and R. J. Teweles, "In Futures Game", edited by B. Warwick, $3^{\text {rd }}$ ed., New York, McGraw-Hill, 1998. 